Invited Paper

\title{
AMORPHOUS METALLIC ALLOYS: A NEW ADVANCE IN THIN-FILM DIFFUSION BARRIERS FOR COPPER METALLIZATION
}

\author{
E. Kolawa, J.S. Reid, and J-S. Chen \\ California Institute of Technology \\ Dept. of Electrical Engineering \\ Pasadena, CA 91125
}

\section{INTRODUCTION}

Copper, which has a lower electrical resistivity and a higher resistance to electromigration than aluminum, is currently being evaluated for ULSI applications as a replacement for aluminum. Drawbacks to the use of copper include its strong tendency to oxidation, a high mobility in metals and semiconductors, and a high reactivity with silicon at temperatures as low as $200^{\circ} \mathrm{C}$.

To overcome these problems, very effective diffusion barriers need to be developed. These barriers should have a low diffusivity for copper, a high thermal stability, and should lack a driving force for chemical reactions with $\mathrm{Cu}$, silicon or silicides. Unlike aluminum, copper does not form stable intermetallic compounds with the transition metals of the $\mathrm{V}$ and $\mathrm{Cr}$ groups, and the mutual solid solubilities of these metals with $\mathrm{Cu}$ are low, so that these metals would seem to be a logical choice for barrier applications. It has long been known, however, that these arguments are misleading[1]. Previous studies have indeed shown $\mathrm{Cu}$ diffuses through grain boundaries and defects in a tantalum layer and into silicon at a relatively low temperature $\left(450^{\circ} \mathrm{C}\right)$ causing a failure of devices[2,3].

The effectiveness of non-reactive and insoluble tantalum barriers can be improved by adding impurities like oxygen or nitrogen to stuff grain boundaries of the material in order to suppress fast grain boundary diffusion[4]. It is difficult, however to reproducibly improve the effectiveness of barriers by adjusting the level of impurities. Since amorphous alloys lack grain boundaries that can act as fast diffusion paths, they should offer an improved alternative for effective barriers [5-7]. In this paper we report on the properties and diffusion barrier performance of amorphous tantalum and tungsten silicides and tantalum-silicon-nitrogen ternary alloys $[3,8]$ for $\mathrm{Cu}$ metallizations. 


\section{Properties of Amorphous Metallic Thin-FILM BarRIERS}

Tantalum and tungsten silicides are deposited by rf sputtering of $\mathrm{Ta}_{5} \mathrm{Si}_{3}$ and $\mathrm{W}_{5} \mathrm{Si}_{3}$ targets in an argon plasma. The as-deposited film are amorphous, as indicated by both $x$-ray and electron diffraction. The atomic composition of the as-deposited tantalum silicide films is $\mathrm{Ta}_{74} \mathrm{Si}_{26}$. The concentration of oxygen and argon impurities as measured by $2 \mathrm{MeV}{ }^{4} \mathrm{He}$ backscattering spectrometry are approximately 3 and 2 at.\%, respectively. The resistivity at room temperature of the $100 \mathrm{~nm}$ thick $\mathrm{Ta}_{74} \mathrm{Si}_{26}$ film deposited on oxidized silicon is about $230 \mu \Omega \mathrm{cm}$. The crystallization temperature of the $\mathrm{Ta}_{74} \mathrm{Si}_{26}$ films on oxidized silicon is about $900^{\circ} \mathrm{C}$. The crystallization products consist mainly of $\mathrm{Ta}_{2} \mathrm{Si}$ with some addition of metastable $\mathrm{Ta}_{4.5} \mathrm{Si}[9]$. The atomic composition of the as-deposited tungsten silicide film is $\mathrm{W}_{80} \mathrm{Si}_{20}$. This film contains about 2 at.\% oxygen and 2 at.\% argon. Its room temperature resistivity is about $200 \mu \Omega \mathrm{cm}$. The film crystallizes after annealing at $700^{\circ} \mathrm{C}$ for $1 \mathrm{hr}$.

The $\mathrm{Ta}_{36} \mathrm{Si}_{14} \mathrm{~N}_{50}$ films are deposited by rf reactive sputtering of the $\mathrm{Ta}_{5} \mathrm{Si}_{3}$ target in $\mathrm{Ar} / \mathrm{N}_{2}$ gas mixture [8]. Thie film contains about 3 at.\% of argon and below 3 at.\% oxygen. The resistivity of the $\mathrm{Ta}_{36} \mathrm{Si}_{14} \mathrm{~N}_{50}$ film is about 625 $\mu \Omega \mathrm{im}$. The as-deposited film on sapphire substrate is $\mathrm{x}$-ray and TEMamorphous and crystallizes at very high temperature, e.g., $1100^{\circ} \mathrm{C}$. The crystallization product is a mixture of hexagonal $\mathrm{Ta}_{2} \mathrm{~N}$, tetragonal $\mathrm{Ta}_{5} \mathrm{Si}_{3}$ and hexagonal $\mathrm{Ta}_{3}\left(\mathrm{Ta}_{0.28} \mathrm{Si}_{0.72}\right)$ [3].

\section{THERMODYNAMICS}

To predict the thermal stability of amorphous silicides with copper, we have calculated ternary M-Si-Cu phase diagram at $25^{\circ} \mathrm{C}$ and $700^{\circ} \mathrm{C}$ for both $\mathrm{Ta}$ and W. Details of the calculations are described in references 10 and 11 . In those calculations only elemental and binary phases are considered due to the lack of data on possible ternary compounds. In addition, the phases are assumed to have zero homogeneity range and no solid solubility. Metastable silicides were not taken into account.

Figure 1 shows the calculated Ta-Si-Cu and W-Si-Cu ternary phase diagrams for $700^{\circ} \mathrm{C}$. In the W-Si-Cu system, tie lines exist between $\mathrm{Cu}$ and all silicides. In the Ta-Si-Cu systems, tie lines exist between copper and all silicides except the Si-richest compound $\mathrm{TaSi}_{2}$. Alternative possible tie lines which can be obtained by minimal adjustments in the thermodynamic data are given by dotted lines. 


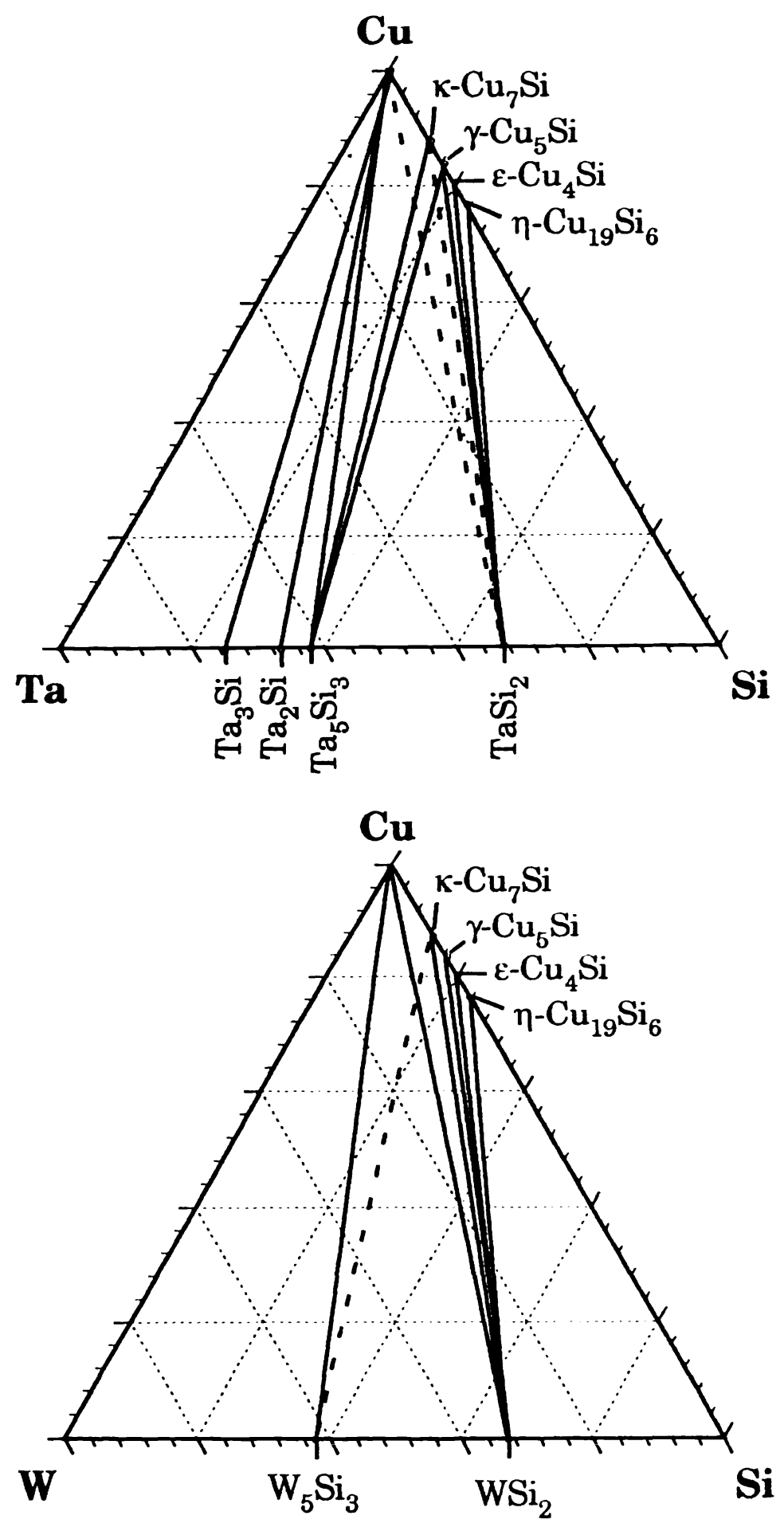

Fig. 1. Calculated Ta-Si-Cu and W-Si-Cu ternary phase diagrams for $700^{\circ} \mathrm{C}$. Dashed lines denote alternate sets of thre possible lines. 
These diagrams reveal what kind of silicides should be chosen for $\mathrm{Cu}$ diffusion barriers in order to obtain a stable system. Specifically, according to the thermodynamics, tantalum and tungsten silicide diffusion barriers with at least $62.5 \%$ atomic metal contact should be used to prevent reaction with copper. An additional benefit of choosing metal-rich silicides lies in the fact that they tend to have higher crystallization temperature than their silicon-rich analogues[11].

\section{DIFFUSION BARRIERS}

Amorphous, metal-rich tantalum silicide possesses all three requirements needed for good diffusion barrier for copper. It is amorphous, so diffusivity for $\mathrm{Cu}$ should be low; it's crystallization temperature is high enough for most barrier applications $\left(\sim 900^{\circ} \mathrm{C}\right)$, and it is thermodynamically stable with $\mathrm{Cu}$.

Figure 2 shows the $I(V)$ characteristics of a shallow $n^{+} p$ junction with the contact configuration $\mathrm{Si}$ substrate $/ \mathrm{Ta}_{74} \mathrm{Si}_{26}(100 \mathrm{~nm}) / \mathrm{Cu}(500 \mathrm{~nm})$ as a function of temperature for $30 \mathrm{~min}$ vacuum annealing. The reverse leakage current of the diodes remains almost unchanged after annealing at $600^{\circ} \mathrm{C}$. Diodes are shorted after annealing at $650^{\circ} \mathrm{C}$. Backscattering spectra of the same metallization deposited on plain silicon confirm that the barrier fails structurally at $650^{\circ} \mathrm{C}$ but is maintained at $600^{\circ} \mathrm{C}$ and below.

The $650^{\circ} \mathrm{C}$ failure temperature is unexpectedly low since the amorphous $\mathrm{Ta}_{74} \mathrm{Si}_{26}$ alloy crystallizes at $900^{\circ} \mathrm{C}$. To elucidate the reason, $\mathrm{Ta}_{74} \mathrm{Si}_{26}$ films with a $\mathrm{Cu}$ overlayer were deposited on oxidized silicon substrates and heated for $1 \mathrm{hr}$ up to $1000^{\circ} \mathrm{C}$. Figure 3 graphically summarizes the x-ray diffraction data after heat treatment for various thicknesses of the copper overlayer. It is clear from the graph that even a thin $\mathrm{Cu}$ overlayer lowers the crystallization temperature from about $900^{\circ} \mathrm{C}$ to $700^{\circ} \mathrm{C}$. No copper silicides were observed in any samples investigated, which agrees with the predicted stability of $\mathrm{Cu}$ with tantalum-rich tantalum silicides. The likely scenario is that $\mathrm{Cu}$ promotes the crystallization of $\mathrm{Ta}_{74} \mathrm{Si}_{26}$ and that the barrier failure is connected with the (partial) crystallization of the barrier and the occurrence of rapid diffusion of copper into silicon via grain boundaries.

Similar results hold for tungsten silicide. The crystallization temperature of a plain $\mathrm{W}_{80} \mathrm{Si}_{20}$ film for $1 \mathrm{hr}$ vacuum annealing is about $700^{\circ} \mathrm{C}$. If a $\mathrm{Cu}$ overlayer induces premature crystallization in this system also, a reduced failure temperature of the amorphous $\mathrm{W}_{80} \mathrm{Si}_{20}$ barrier with a $\mathrm{Cu}$ overlayer is 


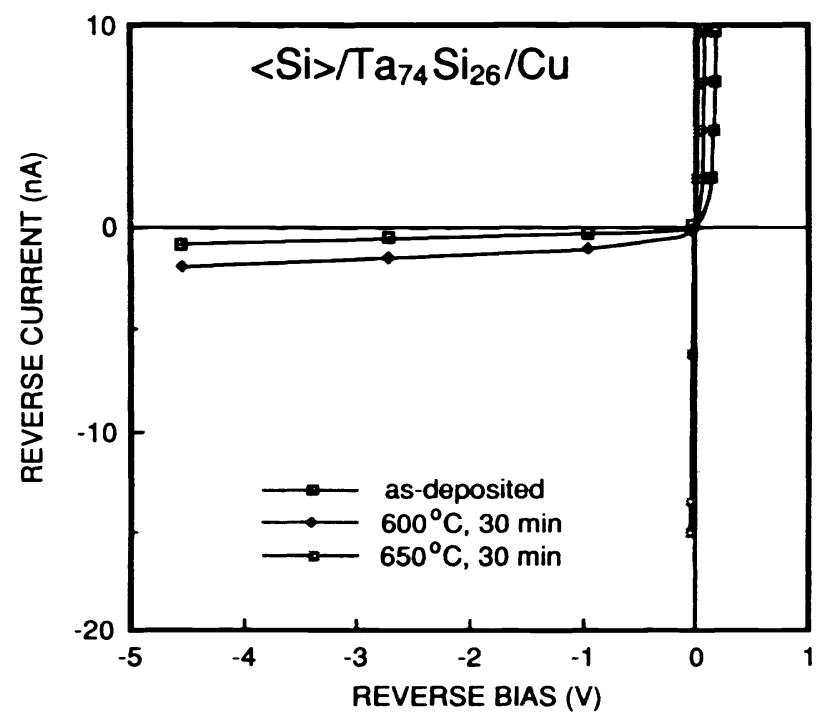

Fig. 2. The I-V characteristics of a shallow $n^{+} p$ junction with a contact structure $<\mathrm{Si}>\mathrm{Ta}_{74} \mathrm{Si}_{26}(100 \mathrm{~nm}) / \mathrm{Cu}(500 \mathrm{~nm})$ as a function of temperature for $30 \mathrm{~min}$ vacuum annealing. The contact area is about $230 \times 230 \mathrm{\mu m}^{2}$.

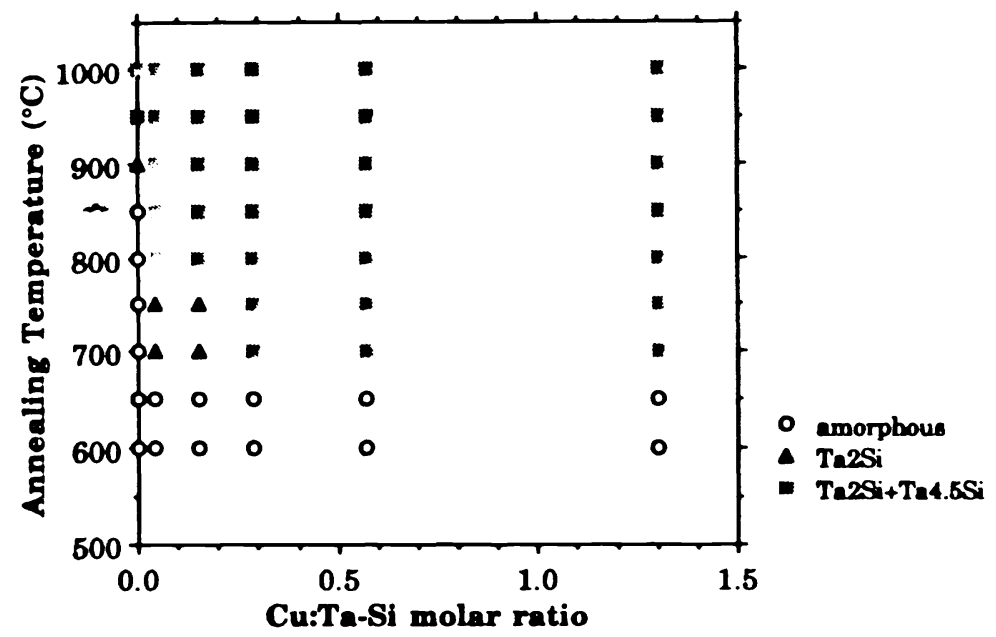

Fig. 3. Graphical summary of the compounds detected by x-ray diffraction after annealing a Ta74 $\mathrm{Si}_{26} / \mathrm{Cu}$ bilayer in vacuum for $1 \mathrm{hr}$ with various copper overlayer thicknesses. At temperatures greatrer than $850^{\circ} \mathrm{C}$, some copper was lost through evaporation. 
expected. Indeed, electrical measurements reveal that the $\mathrm{Si} / \mathrm{W}_{80} \mathrm{Si}_{20}(100$ $\mathrm{nm}) / \mathrm{Cu}(500)$ metallization fails already after $30 \mathrm{~min}$ annealing at $550^{\circ} \mathrm{C}$ in vacuum[12].

The high crystallization temperature of $\mathrm{Ta}_{36} \mathrm{Si}_{14} \mathrm{~N}_{50}$ alloy films $\left(1000^{\circ} \mathrm{C}\right)$ suggests a potentially very high effectiveness of these films as diffusion barriers for $\mathrm{Cu}$. However, the accelerated crystallization observed for the $\mathrm{Ta}_{74} \mathrm{Si}_{26}$ and $\mathrm{W}_{80} \mathrm{Si}_{20}$ in contact with copper also takes place for $\mathrm{Ta}_{36} \mathrm{Si}_{14} \mathrm{~N}_{50}$ in the $<\mathrm{Si}>/ \mathrm{Ta}_{36} \mathrm{Si}_{14} \mathrm{~N}_{50} / \mathrm{Cu}$ metallization. As shown previously by TEM [3] the crystallization starts at the $\mathrm{Ta}_{36} \mathrm{Si}_{14} \mathrm{~N}_{50} / \mathrm{Cu}$ interface at $900^{\circ} \mathrm{C}$ and progresses in a laterally uniform way throughout the film. Once fully crystallized, the copper rapidly diffuses into silicon substrate and causes a failure of the devices. It should therefore be possible to further increase the time to failure or the failure temperature of the metallization by increasing the thickness of the barrier. Figure 4 shows the $I(V)$ characteristics of the shallow junction with a contact of the structure $\angle \mathrm{Si}>/ \mathrm{Ta}_{36} \mathrm{Si}_{14} \mathrm{~N}_{50}(170) / \mathrm{Cu}(500)$. The metallization is stable after annealing at $900^{\circ} \mathrm{C}$ for $30 \mathrm{~min}$ in vacuum. With the same metallization that is only $120 \mathrm{~nm}$ thick, a $<\mathrm{Si}>/ \mathrm{Ta}_{36} \mathrm{Si}_{14} \mathrm{~N}_{50}$ barrier yields shallow junctions with a 8-fold increased leakage current after a similar heat treatment.

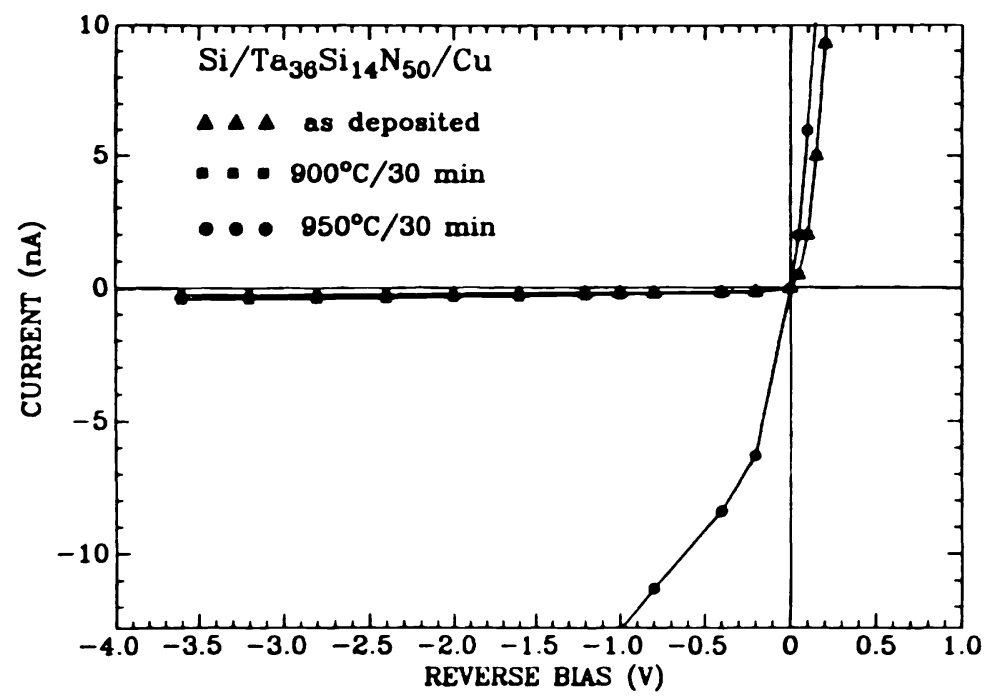

Fig. 4. The I-V characteristic of a shallow $n^{+} p$ junction with a contact structure $<\mathrm{Si}>/ \mathrm{Ta}_{36} \mathrm{Si}_{14} \mathrm{~N}_{50}(170 \mathrm{~nm}) / \mathrm{Cu}(500 \mathrm{~nm})$ as a function of temperature for $30 \mathrm{~min}$ vacuum annealing. The contact area is about $230 \times 230 \mu \mathrm{m}^{2}$. 
In practical application, a contacting layer should be added to the metallization. Since $\mathrm{TiSi}_{2}$ is used in industry, we tested the stability of a $<\mathrm{Si}>\mathrm{TiSi}_{2}(30 \mathrm{~nm}) / \mathrm{Ta}_{36} \mathrm{Si}_{14} \mathrm{~N}_{50}(80 \mathrm{~nm}) / \mathrm{Cu}(500 \mathrm{~nm})$ metallization deposited on the same shallow junction diodes. The reverse current does not change after annealing at $900^{\circ} \mathrm{C}$ for $30 \mathrm{~min}$, and increases about six fold after annealing at $950^{\circ} \mathrm{C}[13]$. The same metallization, but without diffusion barrier, fails at $300^{\circ} \mathrm{C}$.

\section{ConClusions}

Thin films of amorphous metallic alloys can be highly effective diffusion barriers between copper and silicon. However, in order to take advantage of their lack of fast diffusion paths, these barriers must have high crystallization temperatures and be thermodynamically stable with copper.

\section{ACKNOWLEDGEMENTS}

The financial support of the U.S. Army Research Office is gratefully acknowledged. The authors thank Rob Gorris for technical assistance and Rachael Sampley for manuscript preparation .

\section{REFERENCES}

1. M-A. Nicolet, Thin Solid Films, $\underline{52}, 415$ (1978).

2. K. Holloway and P.M. Fryer, Appl. Phys. Lett., 57, 1736 (1990).

3. E. Kolawa, J.-S. Chen, J.S. Reid, P.J. Pokela and M-A. Nicolet, J. Appl. Phys., 70, 1369 (1991).

4. J.E. Baker, R.J. Blattner, S. Nadel, C.A. Evans, Jr., and R.S. Nowicki, Thin Solid Films, 69, 53 (1980).

5. J.D. Wiley, J.H. Perepesko, J.E. Nordman, and K-J. Gus, IEEE Trans. Ind. Electr. 29, 154 (1982).

6. A.G. Todd, P.G. Harris, I.H. Scobey and M.J. Kelly, Solid-St. Electron. 27, 507 (1984).

7. M-A. Nicolet, I. Suni and M. Finetti, Solid State Technol. $\underline{26}, 129$ (1983).

8. E. Kolawa, J. Molarius, C.W. Nieh and M-A. Nicolet, J. Vac.

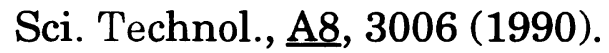

9. J.S. Reid, E. Kolawa, T.A. Stephens, J.-S. Chen and M-A. Nicolet, "Advanced Metallization for ULSI Applications," V.V.S. Rona, R.V. Joshi and I. Ohdomari, eds., (MRS, Pittsburgh, 1992) pp. 285-291.

10. J.S. Reid, E. Kolawa and M-A. Nicolet, J. Mater. Res., 7, 2424 (1992).

11. U. Köster and U. Herold, "Glassy Metals 1," H.-J. Güntherodt and H. Beck, eds., (Springer-Verlag, New York, 1981) pp. 225-257.

12. J.S. Reid (to be published).

13. E. Kolawa, P.J. Pokela, J.S. Reid, J.S. Chen, M-A. Nicolet, R. Ruiz, IEEE El. Dev. Lett., 12, 321 (1991). 